\title{
Quantitative analysis of aqueous phase composition of model dentin adhesives experiencing phase separation
}

\author{
Qiang Ye ${ }^{1}$, Jonggu Park ${ }^{1}$, Ranganathan Parthasarathy ${ }^{1}$, Francis Pamatmat ${ }^{1}$, Anil Misra ${ }^{1,2}$, \\ Jennifer S. Laurence ${ }^{3}$, Orestes Marangos ${ }^{1}$, and Paulette Spencer ${ }^{1,4}$ \\ ${ }^{1}$ Bioengineering Research Center, University of Kansas, Lawrence, Kansas 66045-7609 \\ ${ }^{2}$ Department of Civil Engineering, University of Kansas, Lawrence, Kansas 66045-7609 \\ ${ }^{3}$ Department of Pharmaceutical Chemistry, University of Kansas, Lawrence, Kansas 66047-3729 \\ ${ }^{4}$ Department of Mechanical Engineering, University of Kansas, Lawrence, Kansas 66045-7609
}

\begin{abstract}
There have been reports of the sensitivity of our current dentin adhesives to excess moisture, for example, water-blisters in adhesives placed on over-wet surfaces, and phase separation with concomitant limited infiltration of the critical dimethacrylate component into the demineralized dentin matrix. To determine quantitatively the hydrophobic/hydrophilic components in the aqueous phase when exposed to over-wet environments, model adhesives were mixed with 16, 33, and $50 \mathrm{wt} \%$ water to yield well-separated phases. Based upon high-performance liquid chromatography coupled with photodiode array detection, it was found that the amounts of hydrophobic BisGMA and hydrophobic initiators are less than $0.1 \mathrm{wt} \%$ in the aqueous phase. The amount of these compounds decreased with an increase in the initial water content. The major components of the aqueous phase were hydroxyethyl methacrylate (HEMA) and water, and the HEMA content ranged from 18.3 to $14.7 \mathrm{wt} \%$. Different BisGMA homologues and the relative content of these homologues in the aqueous phase have been identified; however, the amount of crosslinkable BisGMA was minimal and, thus, could not help in the formation of a crosslinked polymer network in the aqueous phase. Without the protection afforded by a strong crosslinked network, the poorly photoreactive compounds of this aqueous phase could be leached easily. These results suggest that adhesive formulations should be designed to include hydrophilic multimethacrylate monomers and water compatible initiators.
\end{abstract}

\section{Keywords}

dentin adhesive; phase separation; water; hydrophobic; hydrophilic

\section{INTRODUCTION}

Water is a major interfering factor when bonding adhesives and/or composites to the tooth. Formation of water blisters and phase separation at the adhesive/dentin interface has appeared as new types of bond defects. ${ }^{1-5}$ The entrapped water droplets may result from water remaining in the adhesive or from the hydrated dentin through the osmotic process, which may be increased by the presence of pulpal pressure. 6,7 The entrapped droplets are

(C) 2012 Wiley Periodicals, Inc.

Correspondence to: Q. Ye; yeq@ku.edu. 
generally on the order of a few microns and detectable on the external adhesive surface ${ }^{8,9}$ or at the adhesive-dentin interface. ${ }^{10,11}$

The droplets that are the result of phase separation are usually larger than the osmotic ones and could remain trapped in the adhesive layer after curing. ${ }^{12}$ This phase reaction has been shown to take place once the solvent begins to evaporate. Large fluid shifts that occur during the bonding process (solvent evaporation and light curing) may allow dentinal fluid to mix with the hydrophilic comonomers, creating nanoleakage pathways within the adhesives. ${ }^{13}$ Such defects have been detected for both total-etch and self-etch adhesive systems in studies using the silver nitrate tracer method and SEM or TEM characterization. These morphologic studies are qualitative and provide no quantitative information on the composition of the aqueous droplets, diffusion/distribution of resin compounds, and the polymerization behavior. The aim of the present investigation was to determine quantitatively the monomers and initiators, present in the aqueous phase of dentin adhesives exposed to over-wet environments. The concentration measurements will provide a more thorough understanding of current adhesive performance and elucidate directions to be taken for further improvement.

\section{MATERIALS AND METHODS}

\section{Model adhesives composition and sample preparation}

The model adhesive consisted of hydroxyethyl methacrylate (HEMA, Acros Organics, NJ) and 2,2-bis[4-(2-hydroxy-3-methacryloxypropoxy)phenyl]-propane (BisGMA, Polysciences, Washington, PA) with a mass ratio of 45/55 (HEMA/BisGMA). ${ }^{4,14,15}$ The photoinitiators used in this study were $0.5 \mathrm{wt} \%$ camphorquinone (CQ) as a hydrophobic photosensitizer and $0.5 \mathrm{wt} \%$ ethyl 4-(dimethylamino)benzoate (EDMAB) as a hydrophobic reducing agent (both from Aldrich, Milwaukee, WI). ${ }^{15}$ All these materials were used as received. Water (HPLC grade, W5SK-4, Fisher Scientific, Fair Lawn, NJ) was added into the neat resins in variable amounts, for example, 16, 33, and $50 \mathrm{wt} \%$. The concentration of water was based on the total final weight of the mixture. Previously, we determined that $\sim 10 \%$ water is the threshold of water/resin (liquid/liquid) phase separation in HEMA/ BisGMA formulations, with a mass ratio of $45 / 55 .{ }^{5}$ Shaking and sonication were required to yield well-dispersed solutions. These turbid mixtures were placed in 1.5-2.0 mL microcentrifuge tubes and further centrifuged (20 min at 10,000g) to obtain clear separated solutions-aqueous phase and resin phase according to the scheme (shown in Figure 1). The lighter aqueous phase (top layer) was transferred using a disposable micropipette. All the operations were carried out at ambient temperature $\left(24^{\circ} \mathrm{C} \pm 1^{\circ} \mathrm{C}\right)$.

\section{Compositional analysis of aqueous phase}

The separated aqueous phase solutions were filtered with a Millipore centrifuge filter device (Ultrafree®-CL, UFC4LCCOO 5000 NMWL, Millipore, Bedford, MA) and a centrifuge (Eppendorf MiniSpin Plus, Eppendorf, Hamburg, Germany) at 3000 RPM. The solutions were refrigerated at $4^{\circ} \mathrm{C}$ until required for compositional analysis. The composition of the aqueous phase was determined separately by reverse-phased high-performance liquid chromatography (RP-HPLC). This technique allows for the separation, identification, and quantification of individual molecules in complex mixtures. ${ }^{16}$ A Shimadzu LC-2010 HTC HPLC system equipped with a SPD-M20A photodiode array detector (PDA), an autosampler with EZStart chromatography software as a controller and for data processing, was used for this study (Shimadzu, Columbia, MD). Separation was performed on a reversephase column-Phenomenex Luna $5 \mu \mathrm{m}$ C18 $4.6 \times 250$ (Phenomenex, Torrance, CA) by elution with $\mathrm{CH}_{3} \mathrm{CN}$ : $20 \mathrm{~m} M$ ammonium acetate buffer. The $\mathrm{pH}$ of the buffer was adjusted to 6.8 with ammonium hydroxide (44273-10×1MLF, Aldrich, Milwaukee, WI). The elution 
was started at a constant flow rate of $0.5 \mathrm{~mL} / \mathrm{min}$ with $\mathrm{CH}_{3} \mathrm{CN}: 20 \mathrm{mM}$ buffer (35:65 v/v) for $30 \mathrm{~min}$ and then ramped linearly to $100 \% \mathrm{CH}_{3} \mathrm{CN}$ within $2 \mathrm{~min}$ and kept constant for $5 \mathrm{~min}$. Twenty microliters of samples were injected onto the HPLC column with a constant column temperature of $40^{\circ} \mathrm{C}$.

Identification and quantitative analysis of components were performed in comparison with the elution time and UV absorption peak intensity of the eluates with those of the individual, known standards. Online PDA is most useful for the analysis of compounds containing chromophores, such as aromatic BisGMA or EDMAB. An illustrative three-dimensional photodiode array display for an aqueous phase sample is provided (Figure 2). The threedimensional data consist of UV absorption spectra from 190 to $350 \mathrm{~nm}$ for each point along the chromatogram. The data can be previewed rapidly for unique absorption regions correlating to specific compounds or functional groups. Independent chromatograms can also be constructed for each wavelength to increase the selectivity of the data. For each monomer or initiator, the wavelength was optimized based on the UV absorption spectra and the concentration in different phases (see Table 1).

Based on the retention times of the initiators/monomers (HEMA $6.2 \mathrm{~min}$, CQ $10.8 \mathrm{~min}$, EDMAB $15.3 \mathrm{~min}$, and BisGMA $20.1 \mathrm{~min}$ ) and UV absorption spectra features, quantifiable amounts of these compounds were detected. It is noted that the dilution ratio typical for an aqueous phase sample was 1:5. This dilution ratio allows us to quantify the small amounts of $\mathrm{CQ}$, EDMAB, and BisGMA, when HEMA concentration was so large as to oversaturate the detector. To determine the HEMA concentration alone, 1:5000 dilution ratio was used.

A representative chromatogram and UV absorption spectrum for BisGMA at $50 \mu \mathrm{g} / \mathrm{mL}$ are shown in Figure 3 (left). The peak at the retention time of 20.1 min was designated as BisGMA. The UV absorption spectrum shows significant UV absorption for wavelengths near 198, 230, and 280nm. The higher wavelength values are usually associated with conjugated structures-for example, the aromatic groups in BisGMA molecules. A similar result has been reported by other investigators. ${ }^{17}$ In our analysis, the limit of quantification $(\mathrm{S} / \mathrm{N} \sim 10)$ is $1 \mu \mathrm{g} / \mathrm{mL}$ for BisGMA at both UV wave lengths of 198 and $280 \mathrm{~nm}$. The range of linearity $(1-400 \mu \mathrm{g} / \mathrm{mL})$ was established by injection of eight concentrations of the reference standards in triplicate (Figure 3, right). In comparison, the range of linearity of HEMA was good only at $10-100 \mu \mathrm{g} / \mathrm{mL}$ (not shown).

\section{Statistical analysis and data processing}

Data from HPLC analysis were obtained in microgram per milliliter for the minor components in the aqueous phase. To convert from microgram per milliliter to weight percentage for the major components, the densities of the samples were measured using an analytical weighing balance with a resolution of $0.01 \mathrm{mg}$ (Mettler Toledo, X205 dual range) equipped with a density kit. ${ }^{18,19}$ For all experimental groups, the differences between compound concentrations (initiator/monomer amounts) were evaluated using one-way analysis of variance (ANOVA), together with Tukey's test at $a=0.05$ to identify significant differences in the means asa function of initial water content.

\section{RESULTS}

Aqueous phase compositions are listed in Table 2. It is note-worthy that the amount of hydrophobic BisGMA, CQ, and EDMAB is very small (converted to weight percentage, they are less than $0.05 \mathrm{wt} \%$ ). BisGMA content in the aqueous phases is $135-542 \mathrm{lg} / \mathrm{mL}$ as a function of initial water content. The amount of photoinitiators CQ and EDMAB in the aqueous phase is about 300 and $100 \mu \mathrm{g} / \mathrm{mL}$, respectively. With the same initial water content, EDMAB concentration is smaller $(\mathrm{p}<0.05)$ than the CQ concentration. The amount 
of BisGMA, CQ, and EDMAB decreased with the increase of the initial water content ( $p<$ 0.01 ). The major components of the aqueous phase are HEMA and water, and the HEMA content ranged from 18.3 to $14.7 \mathrm{wt} \%$. The amount of HEMA in the aqueous phase also decreased with the initial water content $(p<0.05)$.

At least four major peaks were revealed in the HPLC chromatogram for BisGMA, which are attributed to the isomers and homologues of this monomer (Figure 4). Two overlapping peaks were exhibited at relative retention times of 19.6 and $20.1 \mathrm{~min}$. The shoulder peak close to BisGMA was assigned to IsoBisGMA, an isomer of BisGMA. The UV absorbance of IsoBisGMA was found to be identical to that of BisGMA (Figure 4, right). The product associated with the peak at $8.7 \mathrm{~min}$ is derived from BisGMA and could be assigned to BisGMA-H. The structure of the molecule is given in Table 1, and the UV spectrum is presented in Figure 4. It is more hydrophilic, based on its shorter retention time on a reversephased column. The pattern of the profile was slightly different from the UV spectrum of BisGMA, but similar with peaks located near 198, 230, and $280 \mathrm{~nm}$. This assignment was confirmed by mass spectrometry ( $\mathrm{m} / \mathrm{z}$ of 444 , not shown). The other major peak at $27.8 \mathrm{~min}$ was assigned to BisGMA-M, and this peak assignment was also confirmed by mass spectrometry $(\mathrm{m} / \mathrm{z}$ of 580 , unpublished data). To characterize the BisGMA analogues furthermore, the peak intensity ratios of each of the three monomers to genuine BisGMA were calculated to give their relative content in the aqueous phase solution. The values in the neat resin (without water) were also listed as reference (Figure 4, left). They were 0.030 for BisGMA-H, 0.39 for IsoBisGMA, and 0.023 for BisGMA-M. It was found that the IsoBisGMA/BisGMA and BisGMA-M/BisGMA ratios in the aqueous phase were similar to those ratios in neat resin: $0.41-0.44$ for IsoBisGMA and 0.028-0.039 for BisGMA-M. There was a 9- to 31-fold difference in the BisGMA-H/BisGMA ratios in the aqueous phase when compared with the neat resin. However, the BisGMA-H content was still minimal.

\section{DISCUSSION}

The composition of demineralized dentin is $30 \%$ collagen and $70 \%$ water. ${ }^{20}$ With the wetbonding technique, the channels between the collagen fibrils are filled with water, solvent, and oral fluids. Although the clinician may attempt to reduce the moisture content, under in vivo conditions, there is little control over the amount of water within the demineralized dentin matrix. It is possible to leave the dentin surface so wet that the adhesive undergoes physical separation into hydrophobic and hydrophilic-rich phases. ${ }^{3}$

To gain an understanding of phase-separation behavior, compositional analysis of the aqueous phase in model adhesives was performed. The model adhesives are a simple mixture of one hydrophobic comonomer (BisGMA) and one hydrophilic comonomer (HEMA). The composition was based on conventional dentin adhesives. ${ }^{3,21}$ Commercial products were not used, because the variety of unknown additives would interfere with quantitative compositional analysis.

Given that the thickness of the adhesive layer and adhesive/dentin interface is on the order of a few to tens of microns and that the kinetics of the phase separation is governed by diffusion, the time required for mixing and phase separation to occur in these regions is expected to be short compared to that needed for adhesive application on the substrate. ${ }^{22}$ For the bulk volume of adhesive in this study, vigorous shaking and sonication could facilitate mixing with water and promote the rapid formation of dispersed aqueous droplets, thus mimicking the in vivo situation. The trapped aqueous droplets, which are the result of the formation of water blisters and phase separation when the adhesive is applied on wet dentin substrates, are typically small. $., 9,12$ Determining the composition of these droplets in situ may be difficult. In this investigation, liquid-liquid separation of the aqueous and resin 
phases into two distinct layers was achieved by centrifugation. Using this approach, the aqueous phase composition can be determined in a bulk volume.

As expected, when phase separation occurs, hydrophobic BisGMA, CQ, and EDMAB were minimally distributed in the aqueous phase. It is noted that the amount of BisGMA exceeded its solubility in pure water. When immersed in water at $37^{\circ} \mathrm{C}$ for 7 days, BisGMA dissolved at a concentration of $4.1 \mathrm{ppm} .{ }^{23}$ The current BisGMA content in the aqueous phase is much higher (135-542 $\mu \mathrm{g} / \mathrm{mL}$, Table 2 ). This is partly attributable to the higher solubility of BisGMA in the partial organic solvent (15-18\% HEMA) than in pure water. ${ }^{24}$ With the same initial water content, EDMAB concentration is smaller than that of CQ, because it is more hydrophobic than $\mathrm{CQ}$, as judged by its shorter retention time on a reversed-phase column.

The amount of HEMA in the aqueous phase was substantial, 15-18 wt \%. The concentration of HEMA in the aqueous phase had not been determined previously. If the aqueous phase could not be polymerized well, most of the unreacted HEMA would be leached. In fact, the degree of conversion of these solutions as determined by vibrational spectrometry is quite low (unpublished data). This is not surprising due to the low concentration of monomers. In addition, the hydrophobic initiators were distributed in a small amount in the aqueous phase. Unreacted monomers in the aqueous phase with such a low degree of conversion could easily elute into dentinal or oral fluids. ${ }^{13}$

Differences in the diffused monomers or initiators may be due to differences in hydrophilicity and stereochemistry, the flexibility as well as the solubility in separated phases. Small molecules like HEMA have enhanced mobility and will diffuse at a faster rate than larger, bulkier molecules like BisGMA. ${ }^{25}$ Pashley et al. ${ }^{22}$ have determined the diffusion coefficient of HEMA in wet dentin with a value of $1.1 \times 10^{7} \mathrm{~cm}^{2} / \mathrm{s}$, and, based on their calculations, the time necessary for HEMA to diffuse across the 5-6 $\mu \mathrm{m}$ thick demineralized layer is only 1.1-1.6 s. Because the diffusion coefficient of HEMA in aqueous solution should be much larger than that in wet dentin, it is likely that the equilibrium partition of HEMA in the aqueous phase happens within milliseconds. The diffusion rate of BisGMA, CQ, and EDMAB may not be as high as that of HEMA; however, it is presumed that the current experimental procedure (vigorous shaking, sonication and centrifugation) accelerated the near equilibrium partition of these compounds between the separated phases. There are ongoing tests in our laboratory to determine the diffusion rate of these compounds as one measurement that is central to the design and development of durable dentin adhesives that are compatible with the wet, oral environment.

BisGMA is an important component of dental resin because of its chemical and mechanical properties. It has been widely used in dental composites and sealants without characterizing its components. Commercially available BisGMA is, however, a mixture of various compounds. Only one peak in HPLC chromatogram has usually been assigned to the BisGMA monomer. In fact, for BisGMA, at least four major peaks were revealed in our HPLC chromatogram (Figure 4). The method (HPLC/PDA) used in this study was able to identify the different forms and UV spectra of BisGMA. Ohsaki and Imai ${ }^{26}$ have reported that the content of BisGMA-H was $5.0 \mathrm{wt} \%$ in the BisGMA used in their study. Imai et al. ${ }^{27}$ have investigated the concentration of the major components in three commercial BisGMA and six BisGMA-based composite resins using HPLC. Our calculated intensity ratios are very close to their reported content ratios for each of the three monomers to BisGMA.

The IsoBisGMA/BisGMA and BisGMA-M/BisGMA ratios in the aqueous phase were similar to the ratios in neat resin. However, BisGMA-H/BisGMA ratios were $9-31$-fold 
larger in the aqueous phase when compared with the ratios in the neat resin. This could be explained by differences in hydrophilicity, that is, BisGMA-H is more hydrophilic and therefore may diffuse easily into the aqueous phase. However, unlike BisGMA, BisGMA-H is a monomethacrylate as shown in the molecular structure. It could not help to form a crosslinked polymer network in the aqueous phase. In view of the ease of leaching of BisGMA-H into an aqueous environment, more attention should be paid to the minor components contained in commercial BisGMA monomer.

The quantitative determination in our study was only based on one of the major peaks at $20.1 \mathrm{~min}$, not integration of all the peaks simultaneously. This approach was acceptable, because all the major components in commercial BisGMA, with the exception of BisGMA$\mathrm{H}$, have similar hydrophobicity compared to genuine BisGMA. However, BisGMA-H is still relatively hydrophobic, and the concentration in the aqueous phase was minimal; thus, it did not impact the calculated composition.

There are parameters within this study that impair a direct comparison to the clinical condition. For example, the study was conducted at room temperature as opposed to body temperature, neat resin without volatile solvent was used, and the model adhesive represents an idealized condition. It is conceivable that the model adhesive does not conclusively represent the in vivo behavior of commercial products with many more possible interactions between compounds. Although a direct correlation to the clinical condition is not feasible, the results provide clear evidence that water-induced phase separation in adhesives before polymerization should be considered in the development of future materials.

In summary, adhesive phase separation causes incomplete and differential infiltration of the demineralized dentin matrix. ${ }^{3,28}$ The collagen fibrils are not completely protected by the hydrophobic resin polymers, and they will be susceptible to degradation. ${ }^{29-33}$ Water compatible components in adhesive formulations have to be considered, especially the partition of these components in the aqueous environment. In our laboratory, several approaches, such as new monomers with branch structure, ${ }^{34-36}$ solubility enhancer, ${ }^{37,38}$ and water-soluble photoinitiators, ${ }^{14,39}$ have been used to improve the adhesive performance. Future adhesive systems need to be designed carefully to achieve a more homogeneous monomer distribution and conversion within the hybrid layer to overcome the defects associated with phase separation.

\section{Acknowledgments}

We confirm that there are no known conflicts of interest associated with this publication and there has been no significant financial support for this work that could have influenced its outcome.

Contract grant sponsor: National Institute of Dental and Craniofacial Research, National Institutes of Health, Bethesda, MD 20892; contract grant numbers: R01DE14392, 3R01DE014392-08S1, R01DE022054

\section{REFERENCES}

1. Spencer P, Wang Y, Walker MP, Wieliczka DM, Swafford JR. Interfacial chemistry of the dentin/ adhesive bond. J Dent Res. 2000; 79:1458-1463. [PubMed: 11005728]

2. Tay FR, Pashley DH, Yoshiyama M. Two modes of nanoleakage expression in single-step adhesives. J Dent Res. 2002; 81:472-476. [PubMed: 12161459]

3. Spencer P, Wang Y. Adhesive phase separation at the dentin interface under wet bonding conditions. J Biomed Mater Res. 2002; 62:447-456. [PubMed: 12209931]

4. Ye Q, Park JG, Topp E, Wang Y, Misra A, Spencer P. In vitro performance of nano-heterogeneous dentin adhesive. J Dent Res. 2008; 87:829-833. [PubMed: 18719208] 
5. Ye Q, Wang Y, Spencer P. Nanophase separation of polymers exposed to simulated bonding conditions. J Biomed Mater Res B Appl Biomater. 2009; 88:339-348. [PubMed: 18335432]

6. Hashimoto M, Fujita S, Endo K, Ohno H. Effect of dentinal water on bonding of self-etching adhesives. Dent Mater J. 2009; 28:634-641. [PubMed: 19822996]

7. Sauro S, Pashley DH, Montanari M, Chersoni S, Carvalho RM, Toledano M, Osorio R, Tay FR, Prati C. Effect of simulated pulpal pressure on dentin permeability and adhesion of self-etch adhesives. Dent Mater. 2007; 23:705-713. [PubMed: 16904175]

8. Carrilho MR, Tay FR, Donnelly AM, Agee KA, Carvalho RM, Hosaka K, Reis A, Loguercio AD, Pashley DH. Membrane permeability properties of dental adhesive films. J Biomed Mater Res B Appl Biomater. 2009; 88:312-320. [PubMed: 18161803]

9. Van Landuyt KL, Snauwaert J, De Munck J, Coutinho E, Poitevin A, Yoshida Y, Suzuki K, Lambrechts P, Van Meerbeek B. Origin of interfacial droplets with one-step adhesives. J Dent Res. 2007; 86:739-744. [PubMed: 17652202]

10. Tay FR, Lai CN, Chersoni S, Pashley DH, Mak YF, Suppa P, Prati C, King NM. Osmotic blistering in enamel bonded with one-step self-etch adhesives. J Dent Res. 2004; 83:290-295. [PubMed: 15044501]

11. Tay FR, Pashley DH, Suh BI, Carvalho RM, Itthagarun A. Single-step adhesives are permeable membranes. J Dent. 2002; 30:371-382. [PubMed: 12554121]

12. Van Landuyt KL, De Munck J, Snauwaert J, Coutinho E, Poitevin A, Yoshida Y, Inoue S, Peumans M, Suzuki K, Lambrechts P, Van Meerbeek B. Monomer-solvent phase separation in one-step self-etch adhesives. J Dent Res. 2005; 84:183-188. [PubMed: 15668338]

13. Hashimoto M, Ito S, Tay FR, Svizero NR, Sano H, Kaga M, Pashley DH. Fluid movement across the resin-dentin interface during and after bonding. J Dent Res. 2004; 83:843-848. [PubMed: 15505233]

14. Ye Q, Park J, Topp E, Spencer P. Effect of photoinitiators on the in vitro performance of a dentin adhesive exposed to simulated oral environment. Dent Mater. 2009; 25:452-458. [PubMed: 19027937]

15. Ye Q, Spencer P, Wang Y, Misra A. Relationship of solvent to the photopolymerization process, properties, and structure in model dentin adhesives. J Biomed Mater Res A. 2007; 80:342-350. [PubMed: 17001655]

16. Meyer, VR. Practical High-Performance Liquid Chromatography. Wiley; Chichester: 2004.

17. Noda M, Komatsu H, Sano H. HPLC analysis of dental resin composites components. J Biomed Mater Res. 1999; 47:374-378. [PubMed: 10487889]

18. Buruiana T, Buruiana EC, Melinte V, Colceriu A, Moldovan M. Urethane dimethacrylate oligomers for dental composite matrix: Synthesis and properties. Polym Eng Sci. 2009; 49:11271135.

19. Feilzer AJ, Dauvillier BS. Effect of TEGDMA/BisGMA ratio on stress development and viscoelastic properties of experimental two-paste composites. J Dent Res. 2003; 82:824-828. [PubMed: 14514764]

20. Ito S, Saito T, Tay FR, Carvalho RM, Yoshiyama M, Pashley DH. Water content and apparent stiffness of non-caries versus caries-affected human dentin. J Biomed Mater Res B Appl Biomater. 2005; 72:109-116. [PubMed: 15389491]

21. Pashley EL, Zhang Y, Lockwood PE, Rueggeberg FA, Pashley DH. Effects of HEMA on water evaporation from water-HEMA mixtures. Dent Mater. 1998; 14:6-10. [PubMed: 9972145]

22. Pashley DH, Zhang Y, Agee KA, Rouse CJ, Carvalho RM, Russell CM. Permeability of demineralized dentin to HEMA. Dent Mater. 2000; 16:7-14. [PubMed: 11203527]

23. Kim JG, Chung CM. Elution from light-cured dental composites: Comparison of trimethacrylate and dimethacrylate as base monomers. J Biomed Mater Res B Appl Biomater. 2005; 72:328-333. [PubMed: 15529333]

24. Ye Q, Park J, Laurence JS, Parthasarathy R, Misra A, Spencer P. Ternary phase diagram of model dentin adhesive exposed to over-wet environments. J Dent Res. 2011; 90:1434-1438. [PubMed: 21960682]

25. Ferracane JL. Elution of leachable components from composites. J Oral Rehabil. 1994; 21:441452. [PubMed: 7965355] 
26. Ohsaki A, Imai Y. Analysis of major components contained in Bis-GMA monomer. Dent Mater J. 1999; 18:425-429. [PubMed: 10786163]

27. Imai Y, Watanabe M, Ohsaki A. Analysis of major components and bisphenol A in commercial bis-GMA and bis-GMA-based resins using high performance liquid chromatography. Dent Mater J. 2000; 19:263-269. [PubMed: 11218846]

28. Finger WJ, Shao B, Hoffmann M, Kanehira M, Endo T, Komatsu M. Does application of phaseseparated self-etching adhesives affect bond strength? J Adhes Dent. 2007; 9:169-173. [PubMed: 17489477]

29. Spencer P, Swafford JR. Unprotected protein at the dentin-adhesive interface. Quint Int. 1999; 30:501-507.

30. Spencer P, Wang Y, Bohaty B. Interfacial chemistry of moistureaged class II composite restorations. J Biomed Mater Res B Appl Biomater. 2006; 77:234-240. [PubMed: 16193488]

31. Carvalho RM, Chersoni S, Frankenberger R, Pashley DH, Prati C, Tay FR. A challenge to the conventional wisdom that simultaneous etching and resin infiltration always occurs in self-etch adhesives. Biomaterials. 2005; 26:1035-1042. [PubMed: 15369692]

32. Garcia-Godoy F, Tay FR, Pashley DH, Feilzer A, Tjaderhane L, Pashley EL. Degradation of resinbonded human dentin after 3 years of storage. Am J Dent. 2007; 20:109-113. [PubMed: 17542205]

33. Spencer P, Ye Q, Park J, Topp EM, Misra A, Marangos O, Wang Y, Bohaty BS, Singh V, Sene F, Eslick J, Camarda K, Katz JL. Adhesive/dentin interface: The weak link in the composite restoration. Ann Biomed Eng. 2010; 38:1989-2003. [PubMed: 20195761]

34. Park JG, Ye Q, Topp EM, Kostoryz EL, Wang Y, Kieweg SL, Spencer P. Preparation and properties of novel dentin adhesives with esterase resistance. J Appl Polym Sci. 2008; 107:35883597.

35. Park JG, Ye Q, Topp EM, Spencer P. Enzyme-catalyzed hydrolysis of dentin adhesives containing a new urethane-based trimethacrylate monomer. J Biomed Mater Res B Appl Biomater. 2009; 91:562-571. [PubMed: 19582843]

36. Park JG, Ye Q, Topp EM, Misra A, Spencer P. Water sorption and dynamic mechanical properties of dentin adhesives with a urethane-based multifunctional methacrylate monomer. Dent Mater. 2009; 25:1569-1575. [PubMed: 19709724]

37. Guo X, Spencer P, Wang Y, Ye Q, Yao X, Williams K. Effects of a solubility enhancer on penetration of hydrophobic component in model adhesives into wet demineralized dentin. Dent Mater. 2007; 23:1473-1481. [PubMed: 17316781]

38. Guo X, Wang Y, Spencer P, Ye Q, Yao X. Effects of water content and initiator composition on photopolymerization of a model BisGMA/HEMA resin. Dent Mater. 2008; 24:824-831. [PubMed: 18045679]

39. Wang Y, Spencer P, Yao X, Ye Q. Effect of coinitiator and water on the photoreactivity and photopolymerization of HEMA/camphoquinone-based reactant mixtures. J Biomed Mater Res A. 2006; 78:721-728. [PubMed: 16739171] 


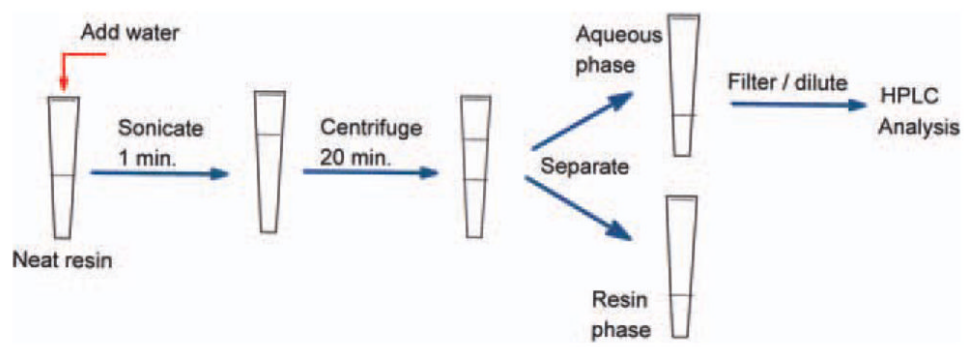

FIGURE 1.

Scheme of sample preparation. [Color figure can be viewed in the online issue, which is available at wileyonlinelibrary.com.] 


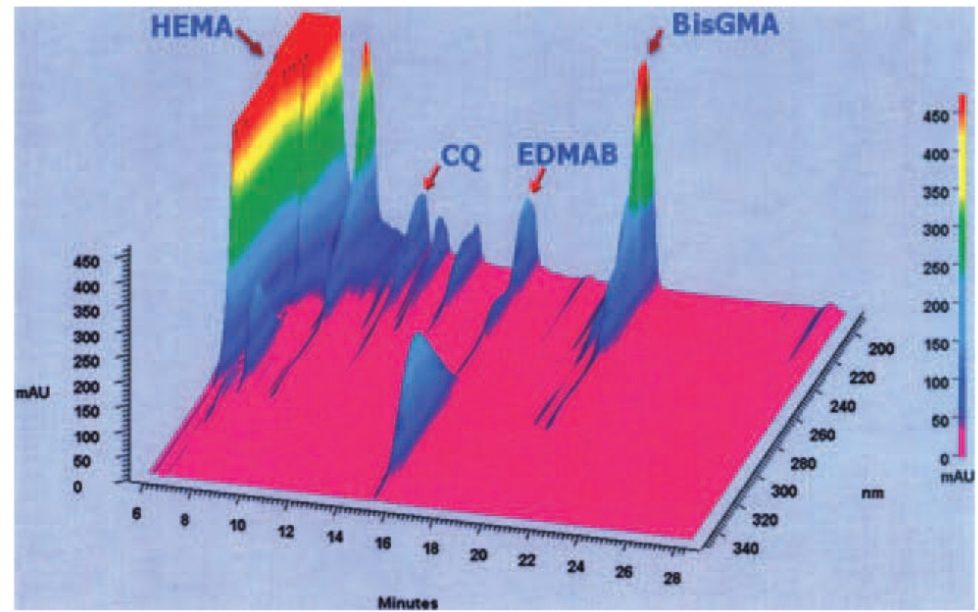

FIGURE 2.

3D display of the photodiode array absorbance of a representative aqueous phase sample. The first dimension is HPLC retention time, second is UV wavelength, and third is absorbance. The data can be rapidly previewed for specific absorbance regions characteristic of functional group. [Color figure can be viewed in the online issue, which is available at wileyonlinelibrary.com.] 

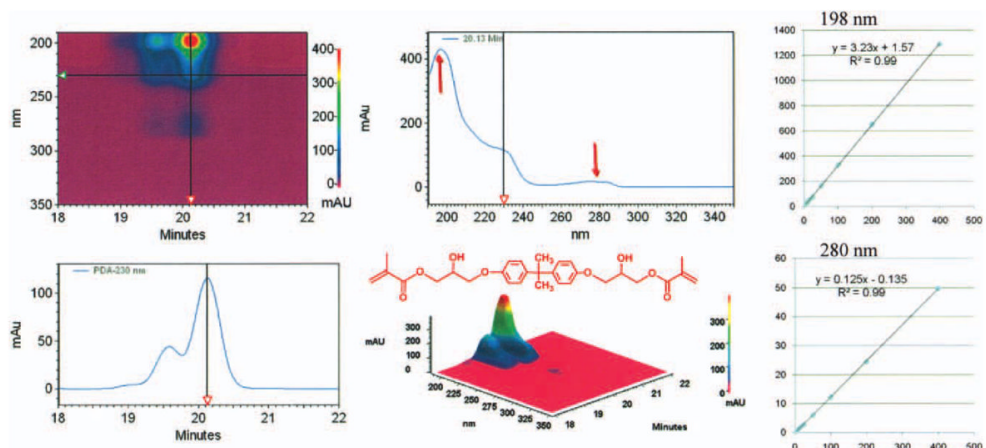

$\infty \quad 280 \mathrm{~nm}$

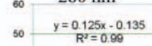

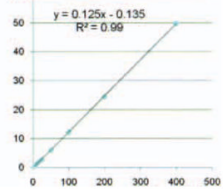

FIGURE 3.

HPLC/PDA analysis for $50 \mu \mathrm{g} / \mathrm{mL}$ BisGMA (left) and the calibration curves of BisGMAAbsorbance $(\mathrm{mAu})$ versus standard concentration $(\mu \mathrm{g} / \mathrm{mL})$ at different $\mathrm{UV}$ wavelengths (right). EZStart chromatography software conveniently displays data results in a single screen for easy viewing. With the optional SPD-M20A PDA control, 3D spectral information is also collected with each run. The bottom left is one representative chromatograph zoomed to show the BisGMA at retention time (20.1 min), and the corresponding ultraviolet spectrum is in the top middle. [Color figure can be viewed in the online issue, which is available at wileyonlinelibrary.com.] 


\begin{tabular}{|c|c|c|c|}
\hline $\begin{array}{c}\text { Initial } \\
\text { Water } \\
\text { Content }\end{array}$ & $\begin{array}{c}\text { BisGMA-H } \\
\text { /BisGMA }\end{array}$ & $\begin{array}{c}\text { IsoBisGMA } \\
\text { /BisGMA }\end{array}$ & $\begin{array}{c}\text { BisGMA-M } \\
\text { /BisGMA }\end{array}$ \\
\hline $\begin{array}{c}16 \%- \\
\text { aqueous }\end{array}$ & 0.26 & 0.41 & 0.028 \\
$(.04)$ & $(.05)$ & $(.006)$ \\
\hline $33 \%-$ & 0.67 & 0.42 & 0.033 \\
aqueous & $(.09)$ & $(.06)$ & $(.007)$ \\
\hline $50 \%-$ & 0.92 & 0.44 & 0.039 \\
aqueous & $(.06)$ & $(.08)$ & $(.005)$ \\
\hline $\begin{array}{c}\text { Neat } \\
\text { Resin }\end{array}$ & 0.030 & 0.39 & 0.023 \\
$(.005)$ & $(.03)$ & $(.003)$ \\
\hline
\end{tabular}

FIGURE 4.

Relative contents of BisGMA homologues (BisGMA, BisGMA-H, IsoBisGMA, and BisGMA-M) in the aqueous phase and their ultraviolet spectra (split for clarity). [Color figure can be viewed in the online issue, which is available at wileyonlinelibrary.com.] 


\section{TABLE I}

The Chemical Structures of Isolated Compounds in the Aqueous Phase and Their Specific Retention Time, UV Detection Wavelength in the HPLC Analysis

\begin{tabular}{|c|c|c|c|}
\hline Product & Retention Time (min) & Wavelength Used (nm) & Molecular Structure \\
\hline HEMA & 6.2 & 208 & 0 \\
\hline BisGMA-H & 8.7 & 198 & \\
\hline CQ & 10.8 & 195 & \\
\hline EDMAB & 15.3 & 311 & \\
\hline IsoBisGMA & 19.6 & 198 & \\
\hline (Genuine) BisGMA & 20.1 & 198 or 280 & \\
\hline BisGMA-M & 27.8 & 198 & \\
\hline
\end{tabular}


TABLE II

Aqueous Phase Composition

\begin{tabular}{|c|c|c|c|c|c|}
\hline \multirow{2}{*}{ Initial Water Content $(\%)$} & \multicolumn{3}{|r|}{ Minor Components } & \multicolumn{2}{|c|}{ Major Component } \\
\hline & BisGMA $(\mu \mathrm{g} / \mathrm{mL})$ & $\mathrm{CQ}(\mu \mathrm{g} / \mathrm{mL})$ & $\operatorname{EDMAB}(\mu \mathrm{g} / \mathrm{mL})$ & HEMA (wt \%) & Water $(\mathbf{w t} \%)$ \\
\hline 16 & $542(22)$ & $313(15)$ & $102^{\#}(10)$ & $18.3 \%(0.8 \%)$ & $\sim 81.6 \%$ \\
\hline 33 & $302^{*}(18)$ & $288^{*}(11)$ & $96^{* \#},(7)$ & $16.8 \%{ }^{*}(0.7 \%)$ & $\sim 83.1 \%$ \\
\hline 50 & $135^{*}(12)$ & $270 *(15)$ & $86^{* \#}(6)$ & $14.7 \%{ }^{*}(1.2 \%)$ & $\sim 85.3 \%$ \\
\hline
\end{tabular}

\# Significantly different from the CQ concentration of the aqueous phase prepared with the same amount of initial water at $a=0.05$.

Significantly different from the concentration of the aqueous phase prepared with initial $16 \%$ water at $a=0.05$. 